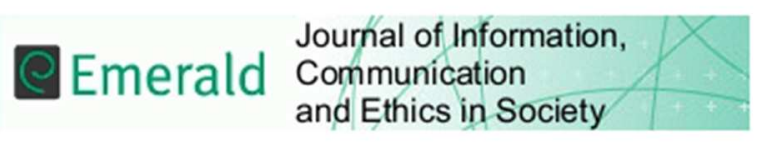

Corporations and Professionalism: Awkward bed-fellows?

\begin{tabular}{|r|l|}
\hline Journal: & Journal of Information, Communication \& Ethics in Society \\
\hline Manuscript ID & JICES-01-2017-0005.R1 \\
\hline Manuscript Type: & Journal Paper \\
\hline Keywords: & Ethics, IT Ethics, Human values \\
\hline \multicolumn{2}{|l}{} \\
\hline
\end{tabular}

SCHOLARONE ${ }^{\text {'t }}$

Manuscripts 


\section{Corporations and Professionalism: Awkward bed-fellows?}

"A corporation may be defined to be a collection of many individuals united into one body, under a special denomination, having perpetual succession under an artificial form, and vested, by policy of the law, with the capacity of acting, in several respects, as an individual, particularly of taking and granting property, of contracting obligations, and of suing and being sued, of enjoying privileges and immunities in common, and of exercising a variety of political rights, more or less extensive, according to the design of its institution, or the powers conferred upon it, either at the time of its creation, or at any subsequent period of its existence."

- Joseph Chitty (1820) A Treatise on the Law of the Prerogatives of the Crown p121

Upon reading this piece by Burmeister I was struck first, and last, by what seems to me to be the core conundrum at the heart of the issues with which it deals. The paper focuses upon (i) a critique of codes of conduct and the value of creating a global code for information and communication technology (ICT) which it supports, (ii) a critique of ICT professional certification - which it supports, and then (iii) explores the debate over whether ICT is really a profession or simply artisan activity, opting for it being a 'young profession'. At each turn the focus upon individual professionalism, and the ethical behavior deemed either central or at least adjunct to it, is contrasted with "corporate settings where their personal professionalism is challenged by corporate business demands". At the heart of these critiques and explorations is the fact that corporate entities are legal fictions whose signatories enjoy limited liability (since the British Limited Liability Act 1855), and not individuals with morals and consciences who must deal personally with the consequences of their actions.

Professionalism, as Burmeister stresses through his quotation from Tinholt et al., is something humans acquire over time, through the activities of their profession and engagement with others: "the very nature of professional work means that some knowledge and skills are best developed through experience, and that an understanding of complex issues, such as ethics, grows with maturity" (Tinholt et al., 2015, p78). Professionalism, thus, is not just associated with, but implies awareness and application of ethics, and adherence to codes of conduct that embody the values of such ethical considerations. As Burmeister succinctly puts it, "For the professional, ethics is just what it means to do your job well on your own terms".

Legal fictions such as limited companies and corporations, by contrast, have no capacity for such growth and maturation. "The notion of limited liability," as Rona puts it, "in creating an actor with a separate personality from those who act under its umbrella, created the vehicle without moral capacity for the realization of a set of doctrines without moral content by the group acting in its name under its umbrella" (Rona 2013.) In other words, there is a fundamental amorality about the socio-economic entity, 'the corporation' (a vehicle that has no moral capacity) that, because the doctrines governing its activities are without moral 
content (profit is king!) is inevitably at odds with individual professionalism, which, by contrast, is inherently moral in character. Professionals, working under the umbrella of corporations, are thus inherently subject to constraints and restrictions on the ethical character of their professionalism.

Contrasting ethical positions are captured in this stand-off (Stahl 2012:641). Defenders of corporations, it may be argued, are adopting utilitarian positions as laid out by Bentham and Mill, asserting that overall utility is maximized when there is more profit, and that entrepreneurial societies over the past two centuries have created more wealth than any other societies in history, massively improving the lives of the many billions of people in the world. Opponents, it may equally be argued, are adopting more Kantian deontological positions, focusing upon the morality and ethics of the intentions of the agents involved. The crux of problem, perhaps, is that whilst individuals are agents with conscience, capable of experience and maturation, and of professionalism, corporations are agents devoid of such characteristics or capacities; they are agents of utilitarianism incapable of a deontological ethical stance. The corporation, therefore, it could be argued, enforces utilitarianism upon those working under its umbrella, contrary to the more deontological character of professionalism.

For Rona, the essence of the problem is in the shift in economic understanding from a practice to a theory. As he says, in the early nineteenth century the shift in the former understanding of economics as "a moral science," to becoming "one of the natural sciences" promoted "the idea that economics as a science may be elaborated without regard to the ethical content of its manifestations," placing "ethics in economic life not only in a substantially reduced, but also in some respects in an entirely new domain" (Rona 2013). In the $20^{\text {th }}$ century this shift became greatly enhanced through the computational calculations of market fundamentalist economics, which argued that all human agents should be understood as 'rational agents' - meaning that human individuals should be regarded as behaving in the manner of corporations, interested ultimately - and amorally - only in their own profit. This characterization of human individuals makes their behaviour susceptible to game theory calculation, and renders economics calculable by computers: economics as a natural rather than a moral science. The outcome is familiar to any critic of contemporary capitalism: "Ethical considerations are expelled from the part of life that is directed at creating the material conditions of well being, and moral sentiments are henceforth seen as 'exogeneous' to the laws governing its pursuit" (Rona 2013).

The notion of Corporate Social Responsibility (CSR), and its lesser but increasingly important sibling, Corporate Data Responsibility (CDR), are the means by which those concerned about such amorality at the heart of our entrepreneurial culture have been attempting, in recent years, to try to redress it. CSR and CDR policies are meant to function as a self-regulatory mechanism whereby corporations monitor and ensure their active compliance with the spirit of the law, ethical standards and national or international norms. 
It might be suggested that embedding CSR and CDR into individual professionalism might help instil such behaviour into corporations - it is, after all, individuals who work in corporations, even those who sit upon the Board of Directors and own and manage them. But the increasingly abstract and globalized nature of corporatism, whereby Boards of Directors are responsible to shareholders who are themselves, increasingly, financial vehicles such as Funds, which are responsible to their investors exclusively for producing profit, rather than individuals with a pride in the company and its activities, means that all considerations of CSR and CDR must inevitably be set below those of the bottom line - regardless of ethical considerations.

The project of IP3, then, surely provides the best hope for promoting the success of individual professionalism, to the extent that its adoption by corporate entities creates the equivalent of a moral and ethical conscience for such legal fictions - a process constituting a brake upon the activities of the company that is more powerful than that of the profit motive. Developing over time with the maturation of the company, this brake would curtail the activities of the company, even to the extent where it may (at least in the short-term) make less money for its shareholders, holding out the hope (with no guarantee) that more profit may result through enhanced reputation, better working practices, happier staff, happier customers, and a healthier working and partnership environment. IP3, in this sense, would enhance CSR and CDR.

Without sanction, however, I fear, and some substantive and reputable regime of surveillance of company activity whereby continued certification was contingent upon good behaviour, IP3 might become a meaningless kite-mark for organisations intent on displaying the correct window-dressing rather than upon acting within the restraints of professional codes of conduct. This may be a tall order. As Burmiester says, in the current climate, "if...values are seen as a code of ethics, and the rest as a code of conduct, then it appears that a global code of ethics is achievable, whereas a global code of conduct is not".

In the final analysis, we must ask the question, why should corporate entities not be legally restrained from behaving unethically, rather than our relying upon relatively ineffective self-regulation? The normativity of the situation is no guide to its ethical or moral rightness - as Stahl reminds us, “'ought' cannot be deduced from 'is'" (Stahl 2012:650). The answer, surely, is in the power that corporations have gained, in our political economy, in the transnational character of their activities and the relative parochialism of national legal frameworks; in the extent to which multinational corporations have written the rules of global trade agreements, to their advantage, over the objections of those who would seek to curtail their activities. Considerations of professionalism in ICT need to be wary of being too functional when addressing corporate realities, and avoid taking "for granted the socio-economic system in which organizations use technology and [failing to] question the justification of distributions of resources and power" (Stahl 2012:650).

Burmeister's conclusion, then, is key: “Until now there has been little recognition of the corporatisation of ICT professionals and the effect that has on their ability 
to engage in appropriate professional ethics. More research is needed to explore appropriate ways in which ethical behaviour can be encouraged in the corporate workplace". This, indeed, is all the more important in the current climate of increasing in-housing of ICT services by corporations.

Many corporations have greatly improved their corporate cultures, and wear the badges of CSR much more than skin-deep (Al-Saggaf et al., 2015). Yet the conundrum at the core of the issues raised in Burmeister's paper, it seems, will continue to present problems for ICT professionals and for the (slow) roll-out of IP3, so long as the power of amoral legal fictions remains unbridled.

\section{$\underline{\text { References }}$}

Chitty, J, (1820) p121 A Treatise on the Law of the Prerogatives of the CrownGoogle Books. https://archive.org/details/atreatiseonlawc01kydgoog

Rona, P (2013) Ethics and the Limited Liability Company. This paper was delivered by Peter Róna at the Von Hügel Institute International Workshop on 'The Economic and Financial Crisis and the Human Person' held at St Edmund's College, Cambridge, 8-9 June 2013. http://www.vhi.st-edmunds.cam.ac.uk/resources-folder/papers-files/paper-WS-rona

Stahl, B.C. (2012) Morality, Ethics, and Reflection: A Categorization of Normative IS Research. Journal of the Association for Information Systems 13(8), 636-656. 